\title{
Research on Patent Strategy of Intelligent Agriculture and Automobile Electronic Information Industry in Jilin Province
}

\author{
Yueying Leng ${ }^{1 \mathrm{a}}$, Yue $\mathrm{Qi}^{2 \mathrm{~b}}$, Min Wang ${ }^{3 \mathrm{c}}$, Xinhui Guan ${ }^{4 \mathrm{~d}}$, Yinan $\mathrm{Hu}^{5 \mathrm{e}}$, Yane Bai* \\ ${ }^{1}$ College of management, Jilin University, Changchun, 130022, China \\ ${ }^{2}$ College of management, Jilin University, Changchun, 130022, China \\ ${ }^{3}$ College of management, Jilin University, Changchun, 130022, China \\ ${ }^{4}$ College of management, Jilin University, Changchun, 130022, China \\ ${ }^{5}$ Guangxi Coast Guard First Detachment, Beihai, 536000, China
}

*Master, Lecturer teaching Computer Base in School, Changchun University of Science and Technology, Changchun, 130022, China

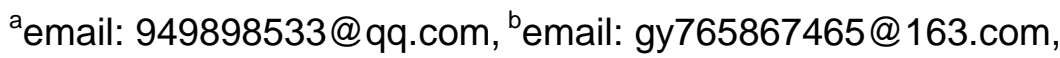

cemail: 296125453@qq.com, demail: 931940102@qq.com,

eemail: 359163253@qq.com, *email:bye1023@126.com

Keyword: Intelligent agriculture electronic; Automobile Electronic; Patent strategy

\begin{abstract}
A patent database about intelligent agriculture and automobile electronic information industry is established in this paper. Then select the data of Jilin Province and establish another patent database. Based on the two patent databases, we can find that the number of patents in Jilin Province in this area is less and the company's patent awareness is weak. On this basis, the SWOT analysis of the intelligent agricultural and automotive electronic information industry in Jilin province is carried out, and the patent strategy of intelligent agricultural and automotive electronic information industry in Jilin province is proposed.
\end{abstract}

\section{Research goal and significance}

The development of electronic information industry can not be separated from the support of technology, at the same time, technology is reflected in the form of patent, so the development of electronic information industry in Jilin province can not be separated from the support of the patent. The patent status of the electronic information industry in Jilin province is studied to develop the corresponding patent strategy in view of the weak links of Jilin province. It is helpful to Jilin province to gain the advantage position in the fierce market competition.

Jilin is a major agricultural province. At the same time, the automobile industry is a pillar industry in Jilin Province. So it is suitable for the patent development strategy of Jilin province to select the patent of intelligent agricultural and automobile electronic information industry.

\section{Retrieval strategy}

In the advanced search of Chinese patent full-text database (CNKI), using fuzzy matching, retrieve TI=“automotive electronics" or "automotive intelligence” or KY="automotive electronics". According to the results of October 19, 2016, there are 5474 results. Based on this data, the patent database of automobile electronic information industry in China is established.

As the same way, retrieve TI=“intelligent agriculture" or "Agricultural Internet of things" or "agricultural sensor” KY=“intelligent agriculture”. According to the results of October 19, 2016, there are 507 results. Then manually remove the patents extraneous to the intelligent agricultural electronic information industry, remaining 498 results. Based on this data, the patent database of intelligent agricultural electronic information industry in China is established.

The two databases have 5972 patents, of which 114 are from Jilin province, Including 110 
automotive electronics related patents and 4 intelligent agricultural related patents. Based on this data, the patent database of electronic information industry in Jilin province is established.

\section{Search results and analysis}

\subsection{Patent analysis of Jilin Province}

\subsubsection{Patent category analysis}

There are 36 invention patents, accounting for 32\%, 77 utility models, accounting for $67 \%$ and only 1 appearance design, accounting for $1 \%$ in the patent database of electronic information industry in Jilin province. As is shown in figure a.

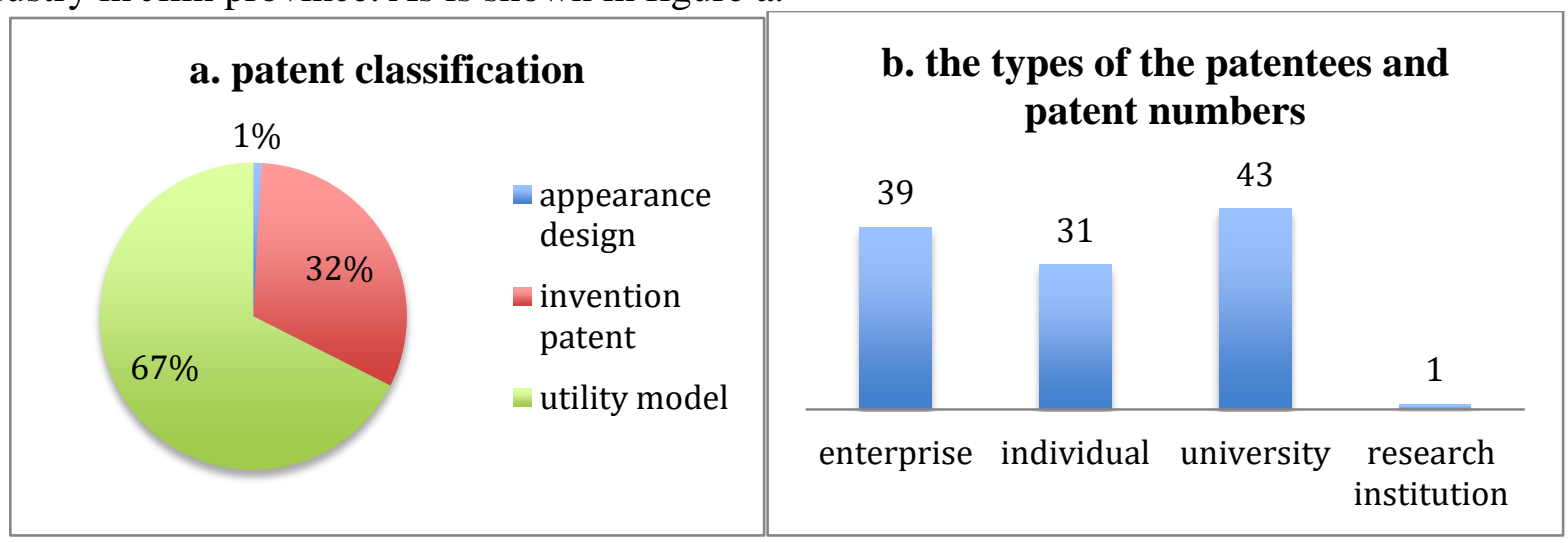

\subsubsection{Analysis of patent right}

The types of the patentees are enterprises, individuals, universities and research institutions. There are 39 enterprises, 31 individuals, 43 universities and only 1 research institution as patentees in the patent database of electronic information industry in Jilin province. As is shown in figure b.

The figure shows that the university has the largest number of patents, accounting for $37.7 \%$ of the total .Enterprises and individuals followed, respectively, accounted for $34.2 \%$ and $27.2 \%$ of the total. The number of patent applications for scientific research institutions is only 1 , which may be related to scientific research institutions in Jilin province are less.

As a patentee, Jilin University has 32 patents, accounting for $74.4 \%$ of all university patentees and accounting for $28.07 \%$ of the total patents. This shows that Jilin University occupies an important position in the intelligent agriculture and automotive electronic information industry and makes a great contribution to the research and development of patent.

In addition to Jilin University, other companies and universities have also applied for a number of patents, but compared with the Jilin University, the number is not too much. The following figure shows the number of patents owned by enterprises and universities.

\begin{tabular}{|c|c|c|c|}
\hline Enterprise & Number & University & Number \\
\hline $\begin{array}{c}\text { Qiming information technology } \\
\text { Limited by Share Ltd }\end{array}$ & 6 & Jilin University & 32 \\
\hline $\begin{array}{c}\text { China's first auto Limited by } \\
\text { Share Ltd }\end{array}$ & 5 & $\begin{array}{c}\text { Changchun University of } \\
\text { Technology }\end{array}$ & 5 \\
\hline China FAW Group Corporation & 4 & Jilin Agricultural University & 3 \\
\hline
\end{tabular}

3.2 Comparative analysis between Jilin province and other provinces

3.2.1 Technology area distribution analysis

In the intelligent agriculture and automotive electronic information industry, the number of patents of Jilin Province is 114, accounting for $1.91 \%$ of the national total quantity, which making up a smaller portion. The number of patents in Jilin province is ranked sixteenth in all provinces of the country, which shows that the research and development of patents in Jilin province are insufficient. The number of patents in other provinces and the proportion are shown in figure c and figure $\mathrm{d}$.

From the charts we can know that our country agriculture intelligent and automotive electronic information industry patent applications are more in Guangdong, Jiangsu, Zhejiang, Shanghai, 
Beijing, Anhui and Shandong. The gap between Jilin province and these provinces is great. To catch up with these provinces, Jilin need to make great efforts to research and development, and take effective patent strategy in related fields to achieve a breakthrough development.

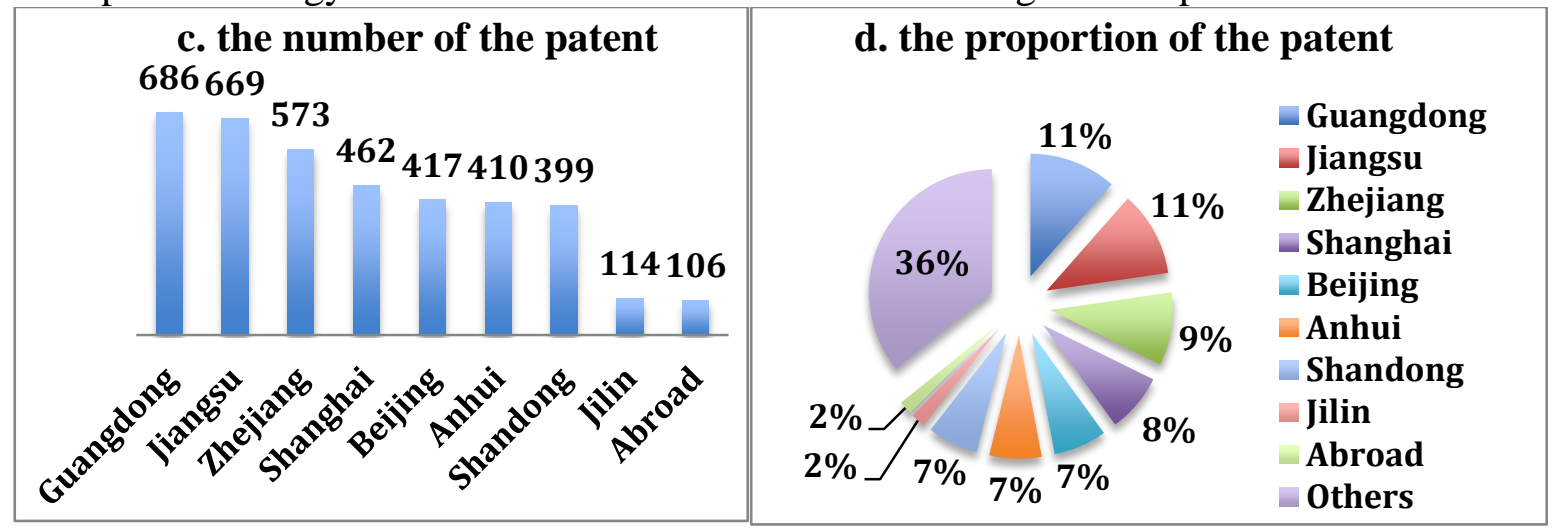

\subsubsection{Technology life cycle analysis}

According to statistics, the patent publication date of agriculture intelligent and automotive electronic information industry patent in Jilin span from 1986 to 2016, of which the number of patents each year is less than 100 between1986 and 2005. Based on patent data from 2006 to 2015, the figure e is the patent technology life cycle of intelligent agriculture and automobile electronic information industry in China.

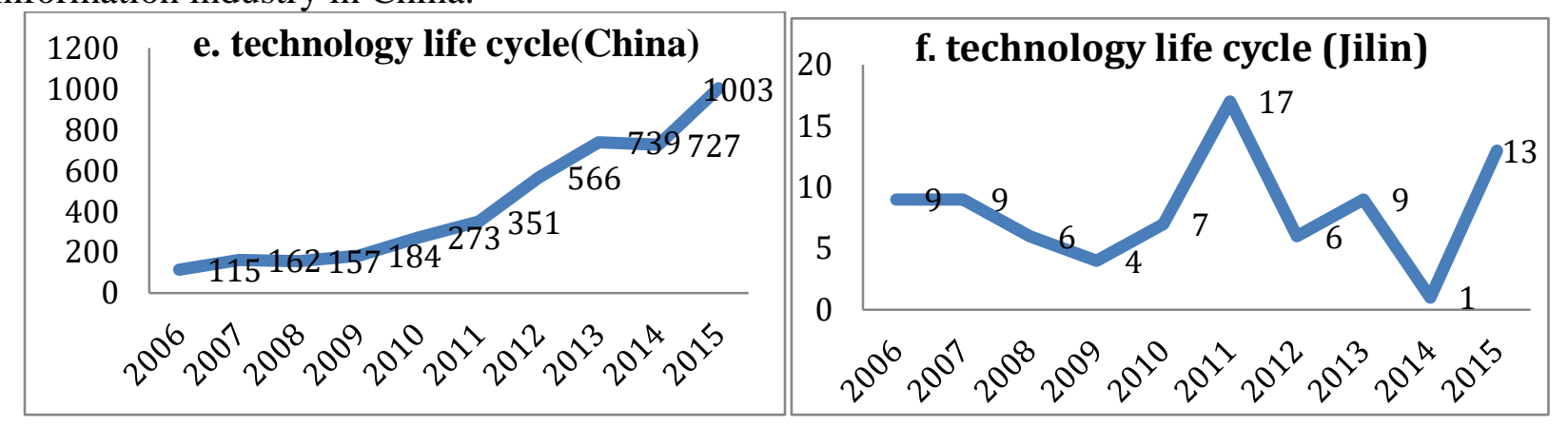

The figure e shows that this technology is in the rising period, the number of patents has increased year by year, despite the decline in 2008 and 2014, but reduced a small number, basically did not have a significant impact on overall trend. The patent rose significantly between 2011 and 2015, except in 2014. The number of patents increased by $37.96 \%$ over the previous year in 2015, and the number of patents in 2016 so far has reached 947, according to the proportion of forecasts, the number of patents in 2016 will exceed 2015. It shows that the technology has been in constant development, and in recent years ushered in the rapid development phase.

In order to compare with the national patent technology life cycle, the patent data of figure $\mathrm{f}$ is from 2006 to 2015, too. Figure $\mathrm{f}$ is the patent technology life cycle of Jilin province. As is shown in the figure, the number of patents fluctuation in Jilin province has great randomness. The number of patents in 2011 and 2015 respectively reached 17 and 13, while the 2014 low to 1 . It shows that the relevant patents in Jilin province has not formed the scale, the number of patent applications is not in line with the general trend. However, the number of patents in 2016 so far has reached 23, more than each year before, which shows that Jilin province has begun to pay attention to patent research on Intelligent Agriculture and automobile electronic information industry, patent related research fields in the future is likely to usher in rapid development stage. 


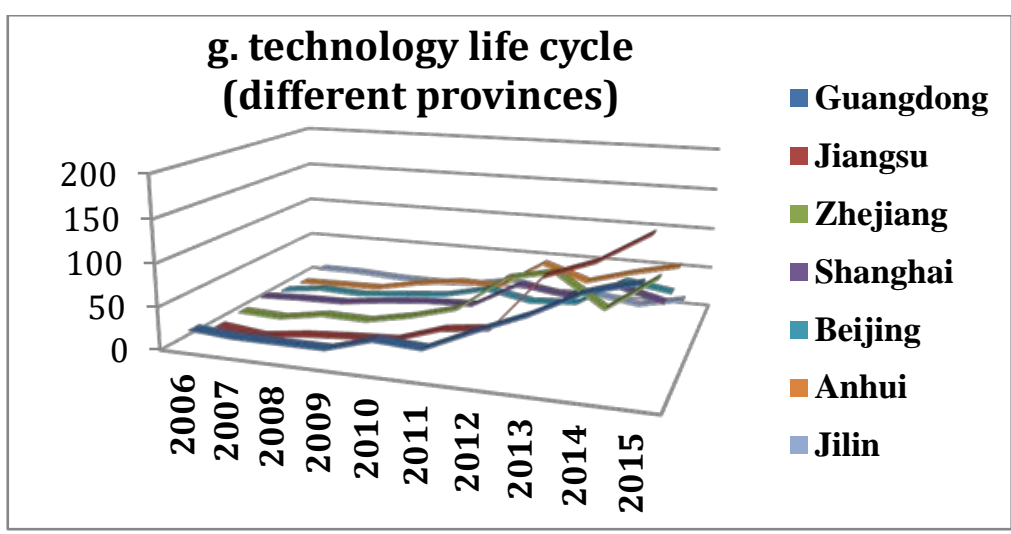

From the figure $\mathrm{f}$, the number of patents in Guangdong province and Jiangsu province keeps rising trend, and the number of patents ahead of other provinces; Zhejiang, Shanghai, Beijing, and Anhui fluctuated upward trend, there will be negative growth in some years, but does not affect the overall upward trend; the patent number of Jilin Province is less and fluctuates greatly, which can not be compared with other provinces at this stage.

\subsubsection{Analysis on the distribution of the patentees}

The analysis of the patentees' distribution is mainly on the statistics and analysis of the patentees with a large number of patents, and compared with the patentees in Jilin province. As a result of large amount of data, more patent owners, and most of the patent owners have fewer patents, only lists the patent number not less than 20 of the patent owner.

\begin{tabular}{|c|c|c|}
\hline Name & Number & Province \\
\hline Chery Automobile Co., Ltd. & 96 & Anhui \\
\hline Zhejiang Geely Automobile Research Institute & 62 & Zhejiang \\
\hline SAIC Motor Corporation Limited (SAIC Motor) & 43 & Shanghai \\
\hline Zhejiang Geely Automobile Research Institute & 38 & Zhejiang \\
\hline Anhui Jiang Huai Automobile Corp & 37 & Anhui \\
\hline Chang'an University & 34 & Shanxi \\
\hline Huizhou DESAY SV Automotive Electronics & 32 & Guangdong \\
\hline Jilin University & 32 & Jilin \\
\hline Dongfeng Motor Corporation & 30 & Hubei \\
\hline Kroraina Dalian Polytron Technologies Inc & 29 & Liaoning \\
\hline Tsinghua University & 28 & Beijing \\
\hline Zhejiang University & 28 & Zhejiang \\
\hline Yanfeng Visteon Automotive Electronics Co. & 28 & Shanghai \\
\hline Chongqing Changan automobile Limited by & 28 & Chongqing \\
\hline BAIC MOTOR & 22 & Beijing \\
\hline Kangmei Oyang & 21 & Chongqing, Shanghai \\
\hline Beijing Hirain science and Technology Co. Ltd. & 20 & Beijing \\
\hline Lei Xin & 20 & Shanghai \\
\hline
\end{tabular}

There are 12 companies, 4 universities and 2 individuals in the table. It shows that enterprises are the main force of patent development, this may be due to patent technology can bring economic benefits for enterprises. Anhui Chery Automobile Co. Ltd has the largest number of patents while Chang'an University is the university with the most patents. Jilin University has 32 patents, ranking second in the University, which shows that patent research in the Jilin University not only occupies an important position in Jilin Province, but also is one of the best in the country.

There are 18 patentees whose patents are more than 20 in the table. Only Jilin University is in Jilin Province. It shows that, in addition to Jilin University, other enterprises, universities and individuals in Jilin Province, do not have a competitive advantage in patent research. 


\section{SWOT analysis of intelligent agricultural and automotive electronic information industry in Jilin Province}

The SWOT analysis method can analyze the advantages, disadvantages, external opportunities and threats of Jilin province. Only on the basis of this, the patent strategy is scientific and feasible.

\subsection{Analysis of advantages}

(1) Jilin province has the basic advantages of developing intelligent agriculture and automobile electronic information industry. Automotive industry is a pillar industry in Jilin Province. At present, Jilin province has formed the economic and Technological Development Zone, Changchun automobile economic and Technological Development Zone, Changchun High-tech Development Zone as the core of the automobile industrial cluster development pattern. In 2012 and 2013, the Jilin province automobile production and sales accounted for more than $10 \%$ of the country. At the same time, Jilin province is a major agricultural province, "12th Five-Year" period, Jilin Province agricultural production conditions improved significantly, agricultural basic facilities investment increased, greatly promote the level of agricultural industrialization.

(2) Colleges and universities, led by Jilin University, have made outstanding contributions to the research and development of intelligent agricultural and automobile electronic information industry in Jilin province. Among the four types of patentees, the universities in Jilin province have the largest number of patents, for 43 , accounting for $37.7 \%$ of the total, one of which ,Jilin University has 32 patents. Jilin University has outstanding scientific research ability and significant advantages in talents cultivation.

\subsection{Analysis of disadvantages}

(1) The enterprise patent strategy consciousness is weak, the scientific research investment is little and the innovation ability is insufficient. The number of patents owned by enterprise patentee in Jilin province is only 39 in the electronic information industry. No enterprise in this field has more than 10 patents. This shows that enterprises do not pay enough attention to the patent strategy, and enterprises are seriously inadequate investment in scientific research. The formulation of patent strategy is related to the future development of the enterprise, and the enterprise must give full attention to it. Only by constantly increasing investment in technological innovation, and progress in the development and protection of patents, that can enable enterprises to gain the competitive advantage and survive in the market.

(2) The brain drain is serious and the enterprise lacks the related personnel. In recent years, due to the economic development of Jilin province is relatively backward, low wage levels, leading to a large number of talented people into the first tier cities, the province's high-end talent shortage. The patent research and development needs a large number of scientific research personnel to participate in, the brain drain is obviously not conducive to the implementation of enterprise patent strategy. The fact that Jilin University has a lot of patents and strong ability of research while the enterprises' patent quantity is significantly reduced indicates that the trained university scientific research personnel do not enter the local enterprises. It shows that enterprises in Jilin province lack a good talent introduction policy.

(3) The development level of agricultural modernization in Jilin province is relatively backward. Jilin province is still in the initial stage of agricultural modernization, only ahead of other central and western provinces, the output index is higher than the national average, and some infrastructure indicators are below the national average. The agricultural development is still extensive, inadequate investment in agriculture, the low cultural quality of the main agricultural production, supporting ability of science and technology on agricultural modernization is far from being released, these are important reasons for restricting the Jilin province agriculture intelligent electronic information industry development.

\subsection{Analysis of opportunities}

Electronic information industry is one of the dominant industries in Jilin province. Jilin Province attaches great importance to the development of electronic information industry, to build the automotive electronics industry cluster in the next few years, to encourage and support the vehicle 
active safety electronics, vehicle control electronics, body electronics and new energy automotive product development and production.

In October 2016, the Jilin Provincial Intellectual Property Association in Changchun was established, the first batch of members including Changchun Research Institute of Applied Chemistry Changchun Branch Technology Development Center, Jilin University, Jilin Tianbang Jinghua intellectual property Operations Services Ltd. Through the "platform + mechanism + industry + capital " of the intellectual property service model, it helps to protect the intellectual property rights, transform the key technology and intellectual property rights to the real productivity, and promote the integration of the development of the industry.

Jilin province emphasis on electronic information Industry and the establishment of Intellectual Property Promotion Association of Jilin province have provided a good opportunity for the development and protection of patent in Jilin province.

\subsection{Analysis of challenges}

(1) Threats from other domestic brands

The patent consciousness of enterprises in Jilin province is weak, and it has not formed a strong attack and defense ability in the patent strategy of intelligent agricultural and automotive electronic information industry. However, a lot of domestic companies, such as Chery Automobile Co. Ltd., Zhejiang Geely Automobile Research Institute Co. Ltd., Shanghai automobile group Limited by Share Ltd have applied for a large number of patents in this area, they have formed their own patent advantage. Enterprises in Jilin province are facing the pressure of competition from these enterprises when they implement the patent strategy in this field.

(2) Threats from the international market

With China's entry into WTO, China's economy continues to open. The electronic information industry in Jilin province is facing the competition not only from domestic enterprises, but also from the global high-tech enterprise patent attacks. In particular, FAW Group, as the global top 500 enterprises, its competitors are not only the domestic automotive group, but also the world automobile multinational corporations. With so many strong competitors, complex international environment and legal system, establishing effective patent strategy is effective measure to ensure the companies' competitive ability.

\section{Patent strategy of intelligent agricultural and automobile electronic information industry in Jilin Province}

The development of intelligent agricultural and automotive electronic information industry in Jilin province has its own advantages and disadvantages. In the face of external opportunities and challenges, only by developing patent strategy according to local conditions, can make Jilin province achieve rapid and efficient development.

\subsection{Enhancing the enterprise patent strategy consciousness}

In view of the problem of weak patent awareness of most enterprises in Jilin Province, the government should actively promote the importance of patent strategy and raise the consciousness of patent strategy. At the same time, encourage enterprises to strengthen the construction of patent information and make the patent strategy suitable for the enterprise's own development. Encourage qualified enterprises to organize personnel to study, exchange and learning in developed areas of the patent. Learning advanced experience in the developed areas of the patent can make the employees fully aware of the deficiencies of the enterprise. Not only can effectively improve the enterprise patent strategy consciousness, but also can effectively improve the level of enterprise's patent strategy by correcting the deficiencies of enterprises.

\subsection{Attach importance to the introduction and cultivation of patent talents}

The introduction and cultivation of high-tech $\mathrm{R} \& \mathrm{D}$ personnel is one of the important means for the implementation of patent strategy. Every year a large number of patent talents graduated from colleges and universities in Jilin. The government should properly guide these talents into local enterprises and prevent the loss of professional talents. Enterprises need to increase investment in 
research, make full use of scientific research personnel, and develop more valuable patented technology. At the same time, the government can develop professional talent introduction plan to attract talents from other provinces into the local enterprise employment. Constantly improving the quantity and quality of professional talents is the intellectual support and guarantee for the implementation of patent strategy in Jilin province.

5.3 Accelerate the construction of agricultural information infrastructure and improve the farmers' knowledge level

Agricultural information infrastructure construction is the basis of Intelligent Agriculture. Speeding up agricultural infrastructure, equipment and information technology is an effective way to promote the development of intelligent agricultural electronic information industry.

Low level of knowledge of farmers is one of the key factors that restrict the development of intelligent agriculture. The government can take various means to solve this problem, for example, regular agricultural technology promotion, agricultural science and technology training seminars, and actively organize farmers to learn all kinds of agricultural knowledge and technology.

5.4 Realize the combination of "production and research" and build regional patent strategy alliance

The enterprise can entrust development or cooperative development mode, carry out the patent cooperation with Jilin University and other Universities. Individual and university patent technology can be paid to authorize the production of relevant enterprises in Jilin Province. This is not only conducive to improving the ability of Jilin Province patent research and development, but also contribute to the industrial transformation of patent technology, and effectively promote the economic development of Jilin province and improve the level of science and technology.

5.5 To shorten the technical gap by using invalid patent

The development of core technology requires a lot of time and money, so the majority of small and medium-sized enterprises in Jilin province does not have independent R \& D capability of patent. However, small enterprises should pay attention to the patent strategy. They can establish a specialized patent intelligence analysis department, in the global scope to retrieve the invalid patent, to filter out the useful patent technology. For example, if a patent expires and loses patent right, then the enterprise does not need to pay the transfer fee to use this patent. Invalid patents include those who have applied for a patent in a foreign country but not in China. These patents are not protected by the law in China, which can be used to analysis the technical content of the foreign patent documents. If the foreign patent applications over the priority protection period but not in Chinese filed, the enterprise can freely use the patent without fear of infringement.

5.6 Imitation of foreign patents, to accelerate the development of patents

Most enterprise's patent research and development is from the beginning of the development of imitation. Learning from the lead developers' experience and their development idea, contribute to further development on the basis of advanced technology. Enterprises can produce superior products in terms of quality and performance, thereby improving their R \& D capabilities to ensure competitive position. At this stage, Jilin Province, in the field of intelligent agricultural and automotive electronics information industry lags behind other provinces.

\section{References}

[1]Jianfeng Cui. Research on the development trend of automobile industry in Jilin Province [A]. Ke Ma. Analysis and forecast of economic and social situation in Jilin in 2015[C].Beijing: Social Sciences Academic Press, 2015.2.32-47

[2]Yuechun Cui, Tianxin Wang. A study on the basic idea and implementation of a strong and prosperous Jilin strategy[A]. Ke Ma. Analysis and forecast of economic and social situation in Jilin in 2015[C].Beijing: Social Sciences Academic Press, 2015.2.175-188

[3]Hongfu Zhao. Study on patent strategy of electronic information industry in Hubei Province [D].Wuhan: Central China Normal University,2009.

[4]Ying Yang,Jinsheng He. Research on patent strategy of automobile industry in China. Modern 
Finance and Economics $[\mathrm{J}]$.2007-01-06

[5]Zhanglin Wang, Shouxia Wang, Ziwei Wang. SWOT analysis and selection of patent strategy of China's new energy automotive industry. Academic Forum $[\mathrm{J}]$, 2015-08-10

[6]Jisheng Yang. Study on patent strategy of automobile industry in Jilin Province. Information Science $[\mathrm{J}] .2010-06$

[7]Yuanyuan Liu. Jilin Provincial Intellectual Property Association established [DB/OL]. http://www.pss-system.gov.cn,2016-10-13

[8]Xingfu Wang. Research on the evolution of automobile electronic technology in China based on patent analysis[D].Wuhan: Wuhan University of Technology,2011

[9]Tengfeng Wu. Study on patent strategy of automotive electronics industry cluster in Jilin Province[D].Changchun:Jilin University,2015.

[10]Haian Huang. Research on the technology forecast of automobile electronics industry in Jilin Province Based on patent analysis[D].Changchun:Jilin University,2014. 